doso en la 1

ar ejemplos a

is funcionalidac uso, dependiende encarnan los conceptos detr por e $\Lambda$ influ
$\mathrm{Pe}$ infin:

Las formas $d r$ oceso de sig ialidad .

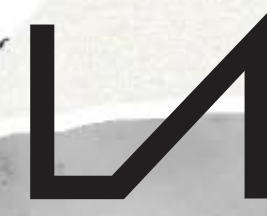

R E V I S A
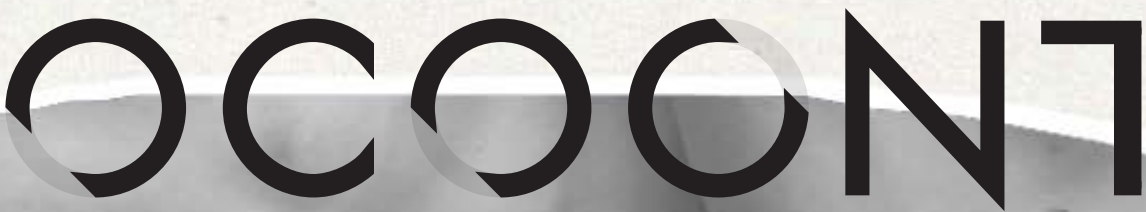

D $E$

No $6 \cdot 2019 \cdot$ ISSN 2386-8449

"El producto del diseñador es un proyecto, el estado previo de un objeto", Entrevista con Norberto Chaves, por Fernando Infante

El papel de la investigación y la teoría en diseño. Una conversación abierta, por Fernando Infante y María Jesús Godoy

UT PICTURA POESIS

Abandonar la escritura. Poesía experimental y manifiesta, Ignacio Gómez de Liaño

PANORAMA: FILOSOFÍA DEL DISEÑO Sección coordinada por Fernando Infante y María Jesús Godoy

Pensar el diseño, Fernando Infante y María Jesús Godoy (Coordinadores)

TEXTOS INVITADOS

Estatus y estado del điseño más allá del objeto, Pedro Medina Reinón

Mar de Nubes, Cuerpo de Cristal, Dionisio González

ARTÍCULOS

Understanding Design Aesthetics beyond Functional Beauty accounts, Lucía Jiménez Sánchez

Estética y diseño industrial: debates y controversias, Joan M. Marín

Del ornamento al delito. El diseño y la sociedad en Charles Baudelaire y Adolf Loos, Jorge López Lloret

When is Architecture not Design? Saul Fisher

Diseño y habitabilidad: una aproximación basada en los lenguajes de patrones, Antonio Hidalgo Pérez

Marcel Breuer: un diseñador global. Experiencias en el ámbito de la vivienda prefabricada, Salvador J. Sanchis, Ignacio Peris y Pedro Ponce Diseño y artes escénicas: el papel de Oskar Schlemmer en Das Triadische Ballett y la actualidad de la Bauhaus, Milagros García Vázquez Lo performativo en prácticas de arte y diseño actuales vinculadas a procesos de innovación social. El caso de La Venezia che non si vede y de La borda, Tània Costa Gomez

Articulaciones de la estética y el diseño. El caso de la evaluación a partir de la investigación dirigida en la carrera de diseño escénico de la Universidad de las Artes de Cuba, Mara Rodríguez Venegas y Xiomara Romero Rojas

SUPLEMENTO

El diseño, la ciudad y un lápiz de labios, Mercedes Espiau, Mar García Ranedo y Alejandro Rojas mas. 


\section{UつCつCNTE}

No $6 \cdot 2019 \cdot \operatorname{ISSN} 2386-8449 \cdot$ DOI 10.7203/LAOCOONTE.5.15381

https://ojs.uv.es/index.php/LAOCOONTE/index

COORDINACIÓN EDITORIAL

Anacleto Ferrer (Universitat de València)

Francesc Jesús Hernàndez i Dobon (Universitat de València)

Fernando Infante del Rosal (Universidad de Sevilla)

SECRETARÍA DE REDACCIÓN

Lurdes Valls Crespo (Universitat de València)

Vanessa Vidal Mayor (Universitat de València)

COMITÉ DE REDACCIÓN

Tamara Djermanović (Universitat Pompeu Fabra), Rosa Fernández Gómez (Universidad de Málaga), Anacleto Ferrer (Universitat de València), Ilia Galán (Universidad Carlos III), Ana María García Varas (Universidad de Zaragoza), María Jesús Godoy (Universidad de Sevilla), Fernando Infante del Rosal (Universidad de Sevilla), Miguel Ángel Rivero (Universidad de Sevilla), Miguel Salmerón (Universidad Autónoma de Madrid), Gerard Vilar (Universitat Autònoma de Barcelona).

COMITÉ CIENTÍFICO INTERNACIONAL

Rafael Argullol* (Universitat Pompeu Fabra), Luis Camnitzer (State University of New York), José Bragança de Miranda (Universidade Nova de Lisboa), Bruno Corà (Università di Cassino), Román de la Calle* (Universitat de València), Eberhard Geisler (Johannes Gutenberg-Universität Mainz), José Jiménez* (Universidad Autónoma de Madrid), Jacinto Lageira (Université Paris 1 Panthéon-Sorbonne), Bernard Marcadé (École Nationale Supérieure d'Arts de Paris-Cergy), Elena Oliveras (Universidad de Buenos Aires y Universidad del Salvador), Pablo Oyarzun (Universidad de Chile), Francisca Pérez Carreño* (Universidad de Murcia), Bernardo Pinto de Almeida (Faculdade de Belas Artes da Universidade do Porto), Luigi Russo (Università di Palermo), Georges Sebbag (Doctor en Filosofía e historiador del surrealismo), Zoltán Somhegyi (University of Sharjah, United Arab Emirates), Robert Wilkinson (Open University-Scotland), Martín Zubiria (Universidad Nacional de Cuyo). *Miembros de la Sociedad Española de Estética y Teoría de las Artes, SEyTA

\begin{tabular}{lll}
\hline DIRECCIÓN DE ARTE & REVISIÓN DE TEXTOS & TRANSCRIPCIÓN DE TEXTOS \\
El golpe. Cultura del entorno & Antonio Cuesta & Álvaro G. Serna
\end{tabular}

(cc) BY Excepto que se establezca de otra forma, el contenido de esta revista cuenta con una licencia Creative Commons Atribución 3.0 España, que puede consultarse en http://creativecommons.org/licenses/by/3.0/es/deed.es

EDITA

\section{SEyTA.}

CON LA COLABORACIÓN DE

\begin{tabular}{|c|c|c|c|}
\hline $\begin{array}{l}\text { VNIVERSITAT } \\
\text { B VALENCIA } \\
\text { Institut te Creativitat } \\
\text { | |nnovacions Educatives }\end{array}$ & $\begin{array}{l}\text { VNIVERSITAT } \\
\text { IE ÖVALENCIA Departament de Filosofia }\end{array}$ & 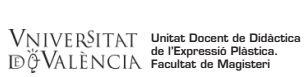 & \\
\hline $\begin{array}{l}\text { DEPARTAMENTO DE ESTÉTICA } \\
\text { E HISTORIA DE LA FLLOSOFIA }\end{array}$ & $\frac{\text { UAW }}{\frac{\text { UNIVRSSIDAD AUTONOMA }}{\text { DE MADRID }}}$ & $\begin{array}{l}\text { Universitat Autònoma } \\
\text { de Barcelona }\end{array}$ & $\begin{array}{l}\text { VNiVERSiDAD } \\
\text { Departamento de Filosofia, Lógica y Estética }\end{array}$ \\
\hline
\end{tabular}

LAOCOONTE aparece en los catálogos: 


\section{LつCつCN7E}

"Cuanto más penetramos en una obra de arte más pensamientos suscita ella en nosotros, y cuantos más pensamientos suscite tanto más debemos creer que estamos penetrando en ella".

G. E. Lessing, Laocoonte o los límites entre la pintura y la poesía, 1766.

Vo hay cól.

létodo, de pen.

:ión en general. Ith

zar la forma para el $\mathrm{n}$.

eptual por las orígenes

la, el objeto, la exposición

storia, porque existe en el $\mathrm{m}$

das sus raíces. Desde alli cc _. panoram

n conceptual y donde el émencia del con 'iseñado, como es el a al objeto y el di $\begin{array}{ll}\text { igen } \mathrm{de}^{\text {to }} \text { la inmer } & \text { tolvidada, o comc } \\ \text { trozo de madera ar }\end{array}$ a manera dorm comunicar ene nundo. Seguin? sngo en manos te el método $C$ les. A partir c teria prima $\mathrm{p}_{\mathbf{c}}$

'xto se puede:

¿ño, en proyea

amientos de $\mathrm{u}$

a conscie-

.)

en la publicación jue "plos de la impor te las nalidades porqu ura un ${ }^{2}$ diendo de qui zenerar $\mathrm{u}$ ción de nr? lne

in-

n-

is.

le http:,

le crear visualidades. A partir de.

ellas la propia materia prima para un en que desde un texto se puede generar $u_{11}$ i

Pensar en diseño, en proyección de nue

posibles comportamientos de una colecti

presente como una consciencia del hecho que estamos elaborando, significac

nuestro entorno (..)

Cardoso, R. C. Rafael. (2014). Design para um mundo complexo. Sãc asil: Cosac Naify. 


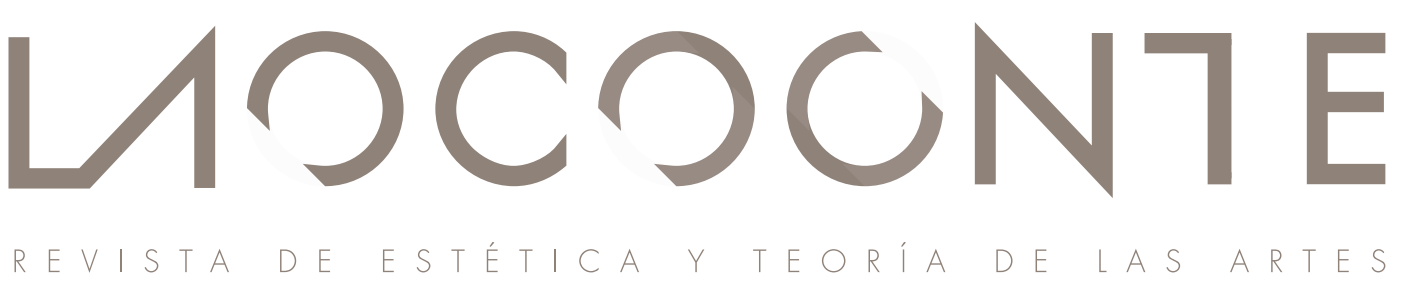

$\mathrm{N}^{\circ} 6 \cdot 2019$

PRESENTACIÓN

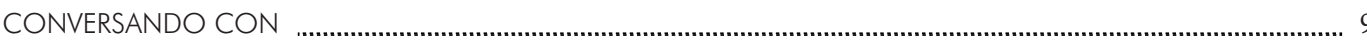

"El producto del diseñador es un proyecto, el estado previo de un objeto", Entrevista con Norberto Chaves,

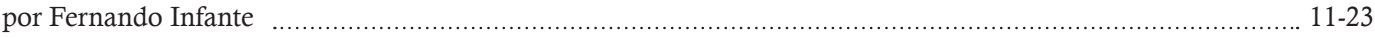

El papel de la investigación y la teoría en diseño. Una conversación abierta, por Fernando Infante

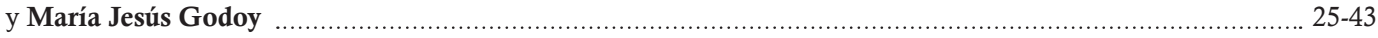

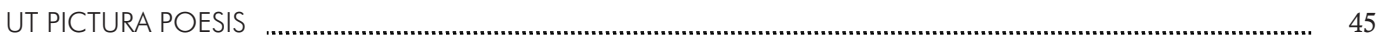

Abandonar la escritura. Poesía experimental y manifiesta, Ignacio Gómez de Liaño ................................................ 47-95

Imágenes de Laocoonte n. 6, de Isadora Gonzaga ................................................................................................... 96-97

PANORAMA

FILOSOFÍA DEL DISEÑO

Pensar el diseño, Fernando Infante y María Jesús Godoy (Coordinadores) .............................................. 101-105

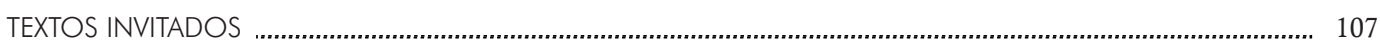

Estatus y estado del diseño más allá del objeto, Pedro Medina Reinón . ................................................... 109-125

Mar de Nubes. Cuerpo de Cristal, Dionisio González .............................................................................. 127-133

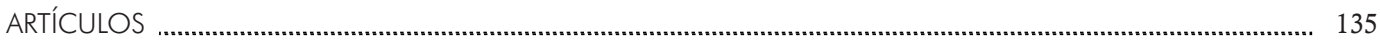

Understanding Design Aesthetics beyond Functional Beauty accounts, Lucía Jiménez Sánchez ................. 137-149

Estética y diseño industrial: debates y controversias, Joan M. Marín _...................................................... 150-164

Del ornamento al delito. El diseño y la sociedad en Charles Baudelaire y Adolf Loos, Jorge López Lloret ... $165-182$

When is Architecture not Design? Saul Fisher ……............................................................................. 183-198

Diseño y habitabilidad: una aproximación basada en los lenguajes de patrones, Antonio Hidalgo Pérez ...... 199-215

Marcel Breuer: un diseñador global. Experiencias en el ámbito de la vivienda prefabricada,

Salvador José Sanchis, Ignacio Peris y Pedro Ponce

Diseño y artes escénicas: el papel de Oskar Schlemmer en Das Triadische Ballett y la actualidad de la Bauhaus, Milagros García Vázquez

Lo performativo en prácticas de arte y diseño actuales vinculadas a procesos de innovación social.

El caso de La Venezia che non si vede y de La borda, Tània Costa Gomez

Articulaciones de la estética y el diseño. El caso de la evaluación a partir de la investigación dirigida en la carrera de diseño escénico de la Universidad de las Artes de Cuba, Mara Rodríguez Venegas

y Xiomara Romero Rojas

SUPLEMENTO 
Walter Gropius. La vida del fundador de la Bauhaus, Jorge Martínez Alcaide

¿Qué significa pensar la política desde la estética? Àger Pérez Casanovas

Ideologías estéticas en los orígenes de la pintura moderna, José Luis Plaza Chillón 300-303

Sobre a estética, Luis Carlos Pereira

Músicas populares. Sociedad y territorio: Sinergias entre investigación y docencia, Mar Aleixandre Badenes.

307-309

La necesidad de la mirada antropológica sobre la literatura, Pablo de Benito David

A propósito de Chandler, o la novela policíaca como tratado filosófico, Juan Evaristo Valls Boix

Videre aude!, Anacleto Ferrer

La inaplazable memoria del dolor y el sufrimiento, Antonio Notario Ruiz

La alargada sombra de la pintura, Raquel Baixauli

Sondear la maravilla, Juan Evaristo Valls Boix

... Y lo sabes, Marc Hernández Montoro

Arqueologías de la modernidad en las artes. Ensayo estético, Carlota Fernández-Jáuregui Rojas

Estética de la Instalación, Luis Cemillán Casis

La Herencia de otra época, María Jesús Godoy Domínguez

Del Theatrum Mundi al Gran Vidrio, Miguel Salmerón Infante

Imágenes de Isadora Gonzaga.

Fotografía de portada de Tamara Djermanovic intervenida por Isadora Gonzaga.

Los coordinadores de la sección Panorama: Filosofia del diseño agradecen

a Antonio Molina Flores su colaboración. 
ner.

llobj vidada, o de ma la publica. los de la im nalidades po ndientn $\mathrm{A}$ -
, la

que e.

usdño, si nn

ज. " da yara el mu tual y d

or enc or las orígenes un tmo, fía del diseño,

rpintero que'curra la forma de

eña Desige para un mundo complexo, de los bienes producidos por el hombre :tores subjetivos también influyen en su

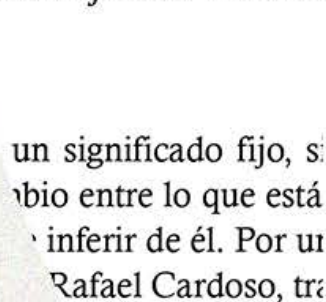

Rafael Cardoso, tri

No hay cómo no e método, de pensa 1, donde la reación en geperal. salizar la forma pa. rue amb ${ }_{\text {Snceptual por }}{ }^{1}$

$$
\text { -rola ol } n^{\prime}
$$

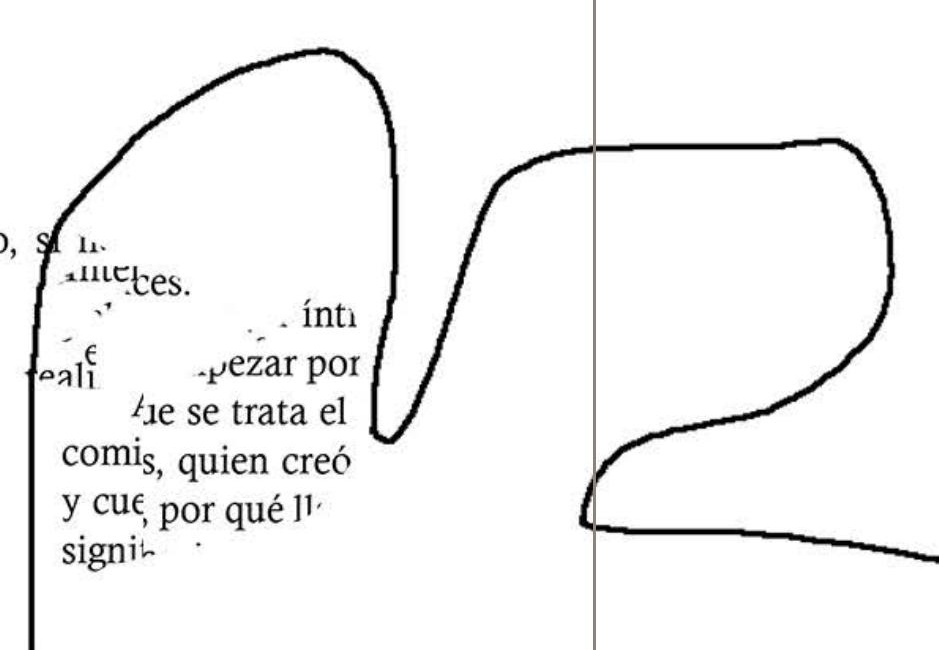

LOCOCNTE

PANORAMA: FILOSOFÍA DEL DISEÑO

Fernando Infante del Rosal y María Jesús Godoy Domínguez

(Coordinadores) 
ner.

ll obj

vidada, o de ma

la publica. los de la im nalidades po ndiendn $\mathrm{N}$ -

\section{, la \\ que e.}

ง. "f y yara el mu tual y d

or enc or las orígenes un tino,

rpintero que'curra la forma de

eña Desigh para un mundo complexo, de los bienes producidos yor el hombre :tores subjetivos también influyen en su

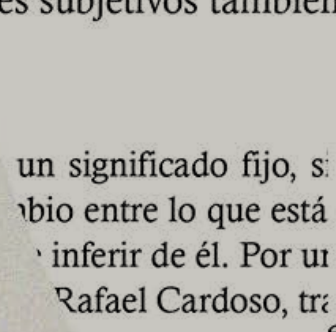

Rafael Cardoso, tri

No hay cómo no e método, de pensa

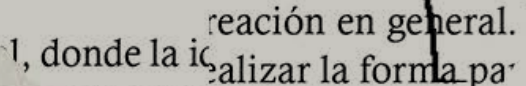
rue ambinceptual por ${ }^{1}$.

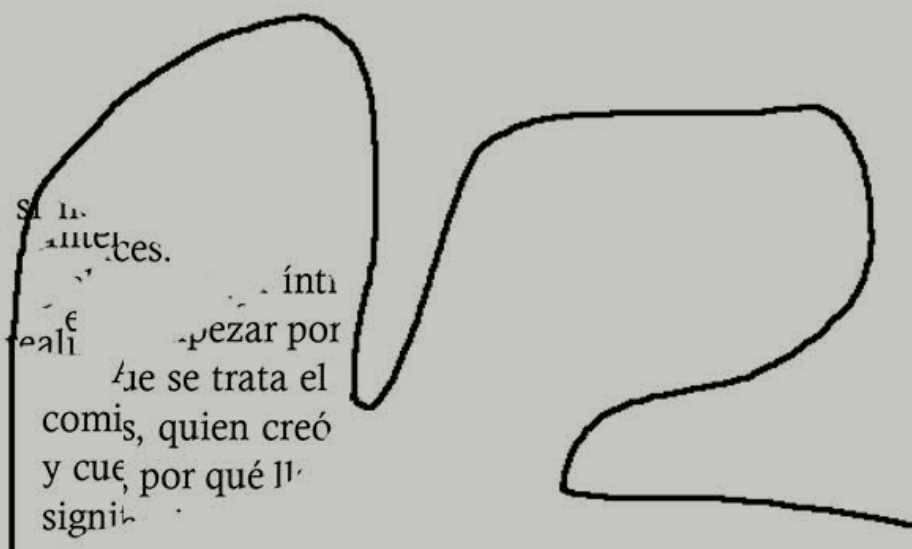




\title{
Pensar el diseño
}

\section{Thinking Design}

Fernando Infante del Rosal ${ }^{*}$ y María Jesús Godoy Domínguez ${ }^{* *}$

\author{
"Ein Zeichen sind wir, deutungslos" \\ [Somos un signo por interpretar] \\ Hölderlin, Mnemosyne
}

El diseño es una de las realidades estéticas más patentes en el abierto arco de nuestra experiencia. Interviene en la conformación de nuestro entorno y define la manera en que nos desenvolvemos en el ámbito de lo consuetudinario. Está asociado a todas las situaciones en las que requerimos la mediación de un signo, de un objeto o de un proceso. Se diseña dando forma, función y significado al espacio, a la luz, al mensaje, a los objetos, a los procedimientos; por eso hablamos de diseño en la arquitectura, la comunicación gráfica, el producto, etc. Pero esta evidencia no ha supuesto hasta ahora una auténtica conciencia del diseño, no al menos al nivel de su presencia. Esto puede deberse a que el diseño es una práctica y una profesión relativamente reciente, aún no separada simbólicamente de la artesanía y del arte a los ojos de la mayoría. Por otra parte, su usual asociación a los modos de producción industriales o tecnológicos dificulta igualmente su percepción como ámbito característico.

Si se asume el carácter extenso de esta realidad estética (entiéndase "realidad estética" como conjunto de hechos y objetos abierto a la apreciación de las cualidades sensibles, más allá de las cualidades estéticas configuradas cultural y socialmente), pensar el diseño significaría hacerse -en el pensamiento- con el modo más amplio en que la realidad y la experiencia son producidas y son dadas en nuestro tiempo. Desvelarlo como el gran mediador, aquel con el que hacemos el entorno y con el que nos hacemos al entorno. Para alcanzar al diseño en esta imagen, antes tendríamos que haber excedido la visión de las particularidades, la inminencia de lo fáctico, del oficio,

* Universidad de Sevilla, ADG-FAD, España.finfante@us.es

* * Universidad de Sevilla, España.godoydom@us.es 
de la disciplina, de los factores de producción,... al final, sorprenderíamos al diseño en una categoría, al nivel de la cultura, quizá como el principal modo de la cultura.

El pensamiento contemporáneo ha sido sensible a estos modos de conformación de la realidad y la experiencia evidenciándolos generalmente como poderosos filtros del encubrimiento. En Ser y tiempo, Heidegger dirigía su crítica a lo que él llamaba publicidad [die Öffentlichkeit] como modo de constitución de lo real:

Distancialidad, medianía y nivelación constituyen, como modos de ser del uno, lo que conocemos como 'la publicidad'. Ella regula primeramente toda interpretación del mundo y del Dasein, y tiene en todo razón. [...] La publicidad oscurece todas las cosas y presenta lo así encubierto como cosa sabida y accesible a cualquiera (Heidegger 2003, $147 \S 27$ ).

Evidentemente, Heidegger no se refiere a la publicidad como medio, a la comunicación publicitaria, sino a un modo de la impropiedad que domina y media todo y nos impide ir "al fondo de las cosas". Similar es la descripción que Hal Foster (2004) hace del diseño como esa realidad pantalla que paraliza un supuesto acceso "a las cosas". Ambas ideas muestran la disposición del pensamiento contemporáneo a la crítica de esas mediaciones generales que obstaculizan como perversiones lo que vendría a ser una experiencia auténtica de la realidad. Las ideas de publicidad en Heidegger y de diseño en Foster muestran, en primer lugar, una tremenda facilidad para transponer un ámbito efectivo -de comunicación, utillaje, hábitat, etc.- a una realidad global. En esto, el pensamiento nunca se ha mostrado apocado, si bien, cuando opera así, lo hace en la forma de la denuncia. La percepción del diseño como un modo de mediación de la realidad se ha producido numerosas veces ya en la filosofía y en la teoría del arte, pero su voluntad de acusación, al tiempo que se percata de la generalidad, niega automáticamente un pensamiento sobre aquello que se concibe como medio. El platonismo contemporáneo posee muchas formas, pero todas coinciden en una cosa: la mediación se les indigesta.

La primera dificultad para pensar el diseño la pone el propio pensamiento, los modos de pensar característicos de la filosofía de nuestro tiempo, que en el ámbito de lo próximo, de la facticidad, de lo circundante, ven todavía sombras, veladuras, pantallas. Los modos del desvelamiento y del acceso siguen rigiendo los valores del pensar, incluso cuando este pretende operar desde el análisis. Diseño sigue siendo, para este modo de pensar, aquello de lo que hay que sustraerse, aquello que hay que sortear. Para él, el diseño está demasiado pegado a los hechos y a los objetos; como dice Heidegger de la publicidad, "oscurece todas las cosas". Probablemente, a esta caracterización del pensamiento de nuestros días se le puedan poner muchas objeciones, no lo dudamos, pero es un hecho que el rechazo del diseño como régimen de inautenticidad está muy generalizado dentro de la filosofía y de la estética.

Por otra parte, podría pensarse que el encumbramiento del arte como régimen de excepcionalidad por parte de estas últimas tiene algo de reclusión y de torre de marfil. Al arte se le considera verdadero modo de acceso -al ser, a la realidad, a la verdadsolo en tanto no esté pegado a aquello a lo que supuestamente da acceso. Con el arte, el pensamiento filosófico muestra una de sus operaciones más determinantes: el pensamiento dispone, es decir, ubica e instala aquello sobre lo que piensa -el arte en este caso-, aunque lo que hace generalmente es consolidar una colocación que se ha dado 
socialmente, afianza el "reparto de lo sensible", en términos de Rancière (2000). Por eso tampoco el arte ha sido propiamente pensado -ahí vuelve de nuevo Heidegger con su conocida consigna: "Lo que más merece pensarse en nuestro tiempo problemático es el hecho de que no pensamos" (2005: 17)-, porque al arte se le concede su enorme apertura desde un espacio simbólico previamente fijado y garantizado. El pensamiento necesita repartos, requiere de la jerarquía que incluye todo espacio. No podemos pensar si no es desde y entre, y el pensar de la filosofía contemporánea -incluso aquella que pretende escapar a esa difuminada "tarea del pensar"- no puede aceptar que ese desde y ese entre estén definidos por otra tarea, la del diseño en este caso. Quizá solo lo acepte cuando un posible Hegel futuro dictamine la muerte del diseño, cuando la lechuza de Minerva se acostumbre a los rótulos de neón y vuelva a identificar el crepúsculo.

A esta tarea de pensar (el diseño) está dedicado el presente número de Laocoonte. Este pensamiento también asume su desde y su entre, tomando en consideración la reflexión que surge entre quienes se dedican profesionalmente al diseño, y desde el diseño como disciplina. La entrevista a Norberto Chaves que ha aparecido en una de las secciones precedentes es buena muestra de ello. También la conversación abierta con investigadores que se han acercado al diseño: su reflexión y su análisis se realiza en una proximidad con el diseño, a partir de la observación de las intencionalidades, los usos del lenguaje y los procedimientos de un ámbito característico (que, por extenso, podemos ver también como un modo de la realidad). Frente a la autoexigida distancia del filósofo y del esteta tradicionales, que paga muchas veces el precio del desconocimiento de los hechos con su posición de observador, estos teóricos conocen los entresijos, los debates, los problemas y los términos y se implican en ellos. De algo sin embargo sí se distancian: del normativismo estético.

Esta sección Panorama: Filosofia del diseño se abre con un texto de Pedro Medina que pretende, precisamente, abrir la comprensión del diseño más allá del discurso objetual mostrando que el propio paradigma actual excede ese ámbito, que la práctica misma del diseño se adentra en un terreno de desmaterialización, consecuencia, entre otras cosas, de la enfatización del diseño como proceso y la aparición de dinámicas colaborativas.

El segundo texto invitado pertenece al artista Dionisio González, que reflexiona habitualmente sobre la arquitectura, tanto desde su obra como desde sus escritos. En este ensayo, su incursión reflexiva busca acceder a las formas de la ciudad y el hábitat despejando los discursos arquitectónicos y urbanísticos, leyendo a través de ellos. Como en su obra visual, aquí Dionisio González atraviesa las formas y los escritos de los arquitectos para alcanzar una especie de arquitectura más allá de la arquitectura.

La sección de artículos, por su parte, cuenta con contribuciones muy diferentes que reflejan la extensión del marco teórico del diseño. La primera de ellas, "Understanding Design Aesthetics beyond functional beauty accounts", es un acercamiento de tipo analítico. En el marco de la reflexión actual de la estética del diseño y desde un punto de vista prácticamente ontológico, la investigadora Lucía Jiménez Sánchez analiza las posibilidades que brinda la teoría de la belleza funcional para la apreciación estética de los objetos de diseño. Concluye así que las consideraciones puramente funcionales defendidas por dicha teoría se quedan cortas a la hora de explicar la dimensión estética del diseño por cuanto en ella entran en juego otro tipo de consideraciones como las propiedades expresivas del objeto que van mucho más allá de las simplemente perceptuales. 
Con una perspectiva más onmiabarcante y aclaratoria, Joan M. Marín aborda críticamente algunos de los debates más interesantes que han tenido lugar en torno al diseño desde el mismo momento de su aparición, a mediados del siglo XIX, y que se prolongan hasta nuestros días con nuevos matices y particularidades. Pasa revista así a la profusa e imbricada relación entre arte y diseño, a la dimensión estética del producto industrial nacido para cumplir una función eminentemente utilitaria y al diseño como supuesto agente de estetización y, por tanto, de estimulación del consumo y sedación de las conciencias. Recalando en el diseño crítico, el diseño ecológico y el diseño para la necesidad, el autor demuestra que el ámbito del diseño es bastante más complejo que el retrato simplista que ofrecen de él estos debates y se extiende más allá de los objetos estupendos de las portadas de las revistas especializadas.

El artículo de Jorge López Lloret recoge un estudio especializado, centrado en la segunda mitad del siglo XIX, época relevante en la historia del diseño de producto, y en la que surgió el problema de la relación entre el fondo y la forma; aquí es donde según el autor se deja sentir la manera en que la sociedad y la cultura tratan a sus individuos, en especial a la mujer. López Lloret analiza las ideas opuestas sobre el diseño que coexistieron en aquella época a partir de Charles Baudelaire, por un lado, en su "Elogio del maquillaje" (1863), como defensa a ultranza del revestimiento que el poeta ve reflejado en la mujer maquillada y a la moda -por opresora que ésta fuera con el sexo femenino-, y Adolf Loos, por otro, en su señera obra "Ornamento y delito" (1908), donde se articula uno de los rechazos más radicales del revestimiento que se extiende a la moda femenina como artificio surgido únicamente, según el arquitecto, para satisfacer al macho adulto.

En un intento por diferenciar la arquitectura y el diseño como disciplinas tradicionalmente confundidas y solapadas, Saul Fischer presenta la arquitectura como un dominio independiente y soberano tanto en lo que se refiere al tipo de objeto que produce -de mayor escala y pensado para la perdurabilidad-, la actividad profesional -más compleja por el nivel de responsabilidad previo y posterior a la producción del objeto- y la carga histórica -más extensa y rica-, como también y sobre todo al pensamiento implicado en la disciplina arquitectónica donde, entre otros factores particulares a calibrar - de los que carecería el diseño-, están la estructura y organización del espacio y, en consecuencia, el impacto ambiental dentro del entorno al que va destinado el producto -el edificio, en su caso-.

Basándose en los lenguajes de patrones del arquitecto y urbanista Christopher Alexander, Antonio Hidalgo Pérez presenta una teoría del diseño como práctica orientada a establecer las condiciones de habitabilidad urbana que debe ir de la mano siempre de la ética y, por lo tanto, un diseño que se sustenta en un modelo o filosofía de la habitabilidad ecológicamente viable. El autor piensa de ese modo el diseño como práctica orientada a satisfacer las necesidades humanas pero en íntima comunión con el concepto de "integridad habitacional" por medio del cual se puede alcanzar el equilibrio a escala planetaria.

Salvador José Sanchis Gisbert, Ignacio Peris Blat y Pedro Ponce Gregorio nos acercan a la figura de Marcel Breuer, quien habiéndose formando en los ideales de la escuela de la Bauhaus, exportó al exiliarse a los Estados Unidos lo mejor de la arquitectura moderna europea, que plasmó en sus viviendas prefabricadas. Con ellas, vino a demostrar según los autores que la modernidad en la arquitectura no la aportaron los materiales o los procesos industriales de producción en serie, sino el cambio de 
actitud de los arquitectos en la manera en que incorporaron en sus proyectos esos nuevos sistemas y materiales, lo que vendría a constituir una verdadera nueva filosofía del diseño.

Por su parte, Milagros García Vázquez dedica su atención al diseño de decorado y vestuario en la obra multidisciplinar de Oskar Schlemmer, miembro destacado de la Bauhaus, tomando como ejemplo la obra escénica Das Triadische Ballett, que, aunque estrenada antes de la constitución como tal de la Bauhaus, fueron Gropius y sus alumnos los que reconocieron su valía en el mundo del teatro y el arte en general.

El artículo de Tània Costa Gomez está dedicado a prácticas artísticas y de diseño actuales -pone como ejemplo La Venecia che non si vede y La Borda- que no sólo pretenden desarrollarse desde la vía participativa, sino que se presentan como agentes de transformación social al incidir directamente en el comportamiento y las estructuras de convivencia colectiva.

Finalmente, Mara Rodríguez Venegas y Xiomara Romero Rojas llevan a cabo una reivindicación del papel de la estética en la formación académica de los estudiantes de Diseño Escénico en la Universidad de las Artes de Cuba planteando numerosos aspectos de la enseñanza artística. Como también destacan Norberto Chaves y los investigadores encuestados, el carácter de la formación en diseño es una clave fundamental.

En la sección Suplemento, que cierra este Panorama: Filosofía del diseño, se incluye un texto sobre el papel que el diseño, gráfico en este caso, puede jugar en la ciudad y en su autopercepción. Mecha Espiau, Mar G. Ranedo y Alejandro Rojas realizan una investigación conjunta que aúna sus tres dedicaciones -la historia del arte, el arte y el diseño gráfico, respectivamente-, en un ejercicio de cooperación más que de multidisciplinariedad.

Uno de los primeros teóricos del cine, el poeta húngaro Béla Balázs, afirmó que ningún arte había sido grande sin teoría. Evidentemente, Balázs no se refería a que el arte, cualquier arte, necesitara de la teoría para hacerse grande, pero sí para mostrar en otros términos su dimensión. La teoría -entendida como una práctica basada en la construcción de ideas, discursos y argumentos- no es imprescindible para que ningún arte se desarrolle, está claro; pero, históricamente, la teoría parece haber cumplido dos funciones cruciales: fomentar la percepción y la comprensión del arte como una realidad que es más que la suma de prácticas y objetos, y fortalecer su territorio endureciendo sus defensas. La teoría del diseño no ha alcanzado la magnitud suficiente como para que sus construcciones hagan más aprehensible y más endurecida la realidad del diseño. Esto puede deberse fundamentalmente a que la propia teoría no ha sido todavía tejida, a que sus hilos no han conformado aún una malla suficientemente cerrada, una urdimbre resistente. Aquí, no obstante, en este número 6 de Laocoonte, empieza a hacerse evidente una textura de referencias, términos, problemas, criterios y conceptos, una comunidad de discurso que ha decidido avanzar pensando el diseño.

\section{Bibliografía}

Foster, H. 2004. Diseño y delito. trad. Alfredo Brotons. Madrid: Verso.

Heidegger, M. 2003. Ser y tiempo. trad. Jorge Eduardo Rivera, Madrid: Trotta. Heidegger, M. 2005. ¿Qué significa pensar? trad. Raúl Gabás, Madrid: Trotta. Rancière, J. 2014. El reparto de los sensible. Estética y politica. trad. M. Padró, Buenos

Aires: Prometeo. 
¿s raír

„ue exir' e es, qui

a concrablot

i ser dica'oniunte

sol

has un us

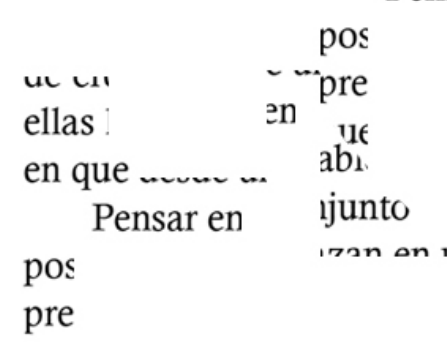

tus

art

ma
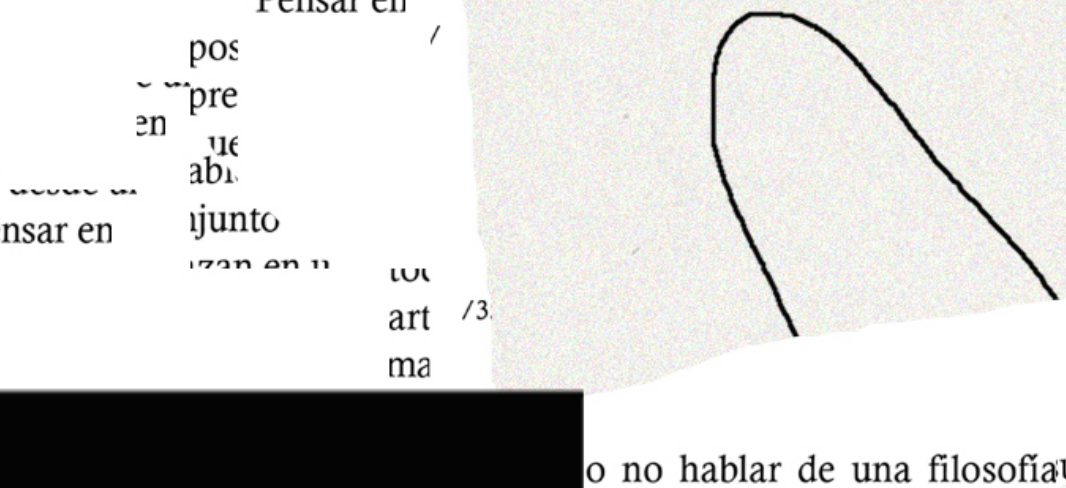

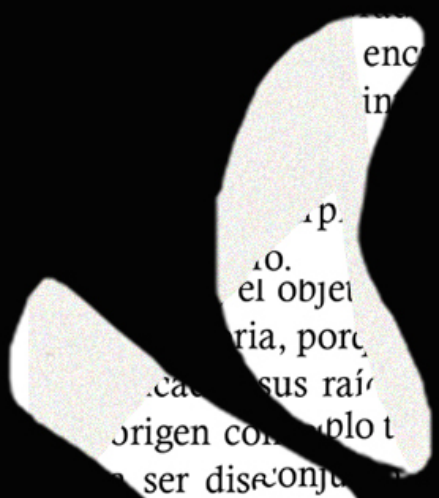

ser disfionj

seventrelazar

Pensa

nfinitame

contrar su.

hacex conscien

de las mas de

hago

?cié

lo que

presente

ralidades.

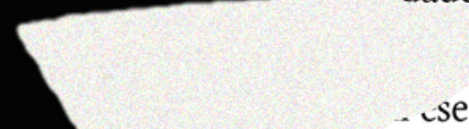

$\rightarrow$ ras que $c$

nenge, para
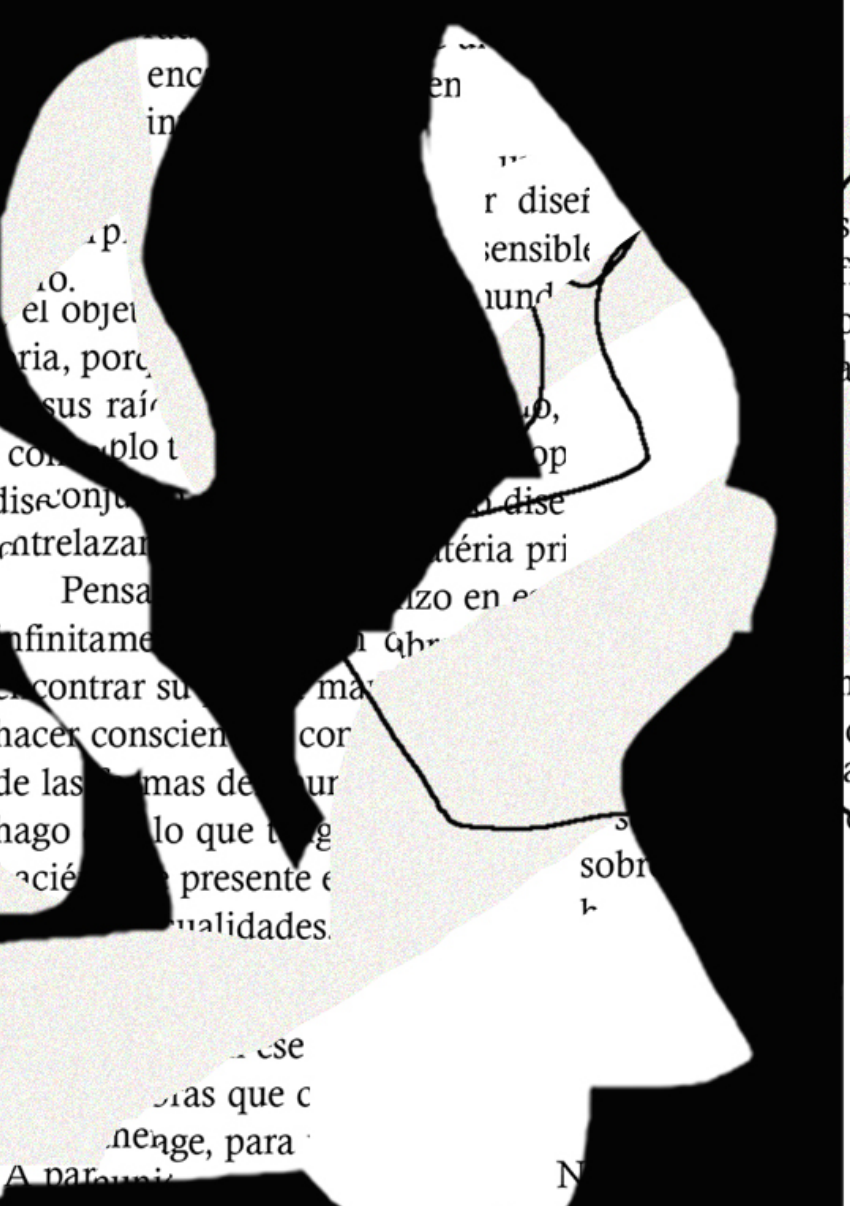

nov

o no hablar de una filosofiav

$\mathrm{Cr}$ Intentaré exponer

rea. el mundo :-

concenes

novg'

su histc.

incadas $s$ '

prigen

a.

ungiv,

do sensibleíaa

o el hilo den carp.

al y urn Curfo.

semo es el panor ma 1

intyanencia del doncep

objeto y el diseñado.

como un carplo

'sa amorfo.

$\eta$ brasileñ ${ }_{\text {no }}$ tier ${ }^{\text {to }}$,

tancia de $e_{\text {el int }}{ }^{\text {irtir de }}$.

No hay cómolos factienc .ma para $\mathrm{u}$ de método, de penso use: $c^{2}$ puede gene creación en general. 1.

en proyección realizar la forma para $\epsilon_{\text {tier }}$ conceptual por las orígs entos de una novela, el objeto, la exr su historia, porque exir.

"cadas sus raír

, en pro para um 1

ientos fincadas sus

origen 


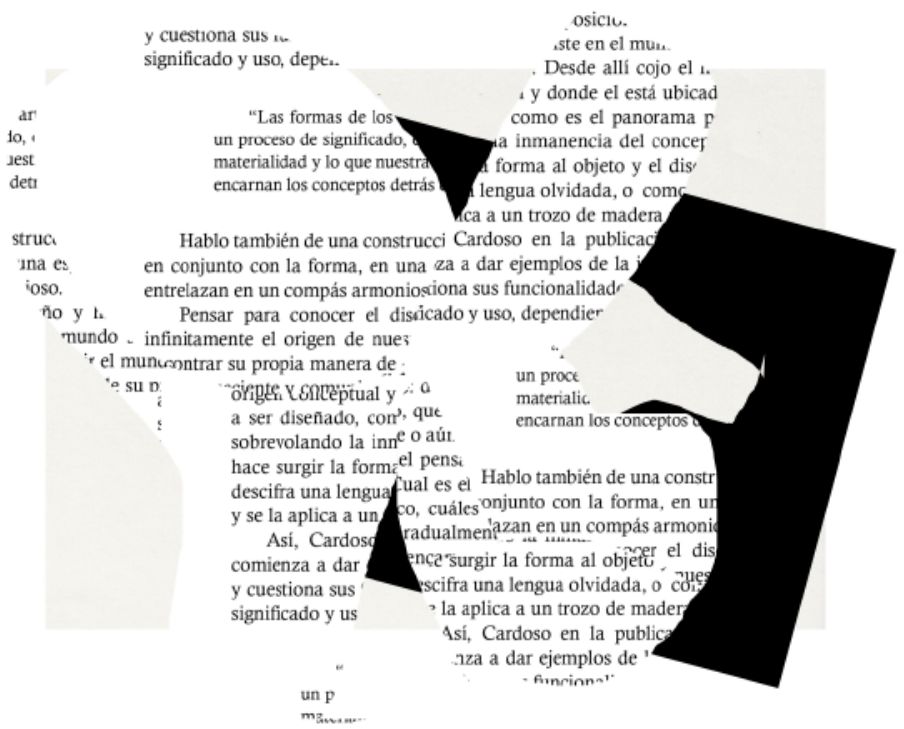

"Lo impreso exige una humildad de espíritu por cuya falta muchas de las bellas artes se tambalean ahora en experimentos de autoconciencia y sensiblería. No hay nada simple ni aburrido en lograr una página transparente. La ostentación vulgar es el doble de fácil que la disciplina".

Beatrice Warde, The Crystal Goblet, or why printings should be invisible (1930)

"El diseño que es objetivo, comprometido con el bien común, bien compuesto y delicado, constituye la base del comportamiento democrático".

Josef Müller-Brockmann, Grid and Design Philosophy (1981) 

EDITA

\section{SEyTA.}

SOCIEDAD ESPAÑLAA
DE ESTETICA Y TEORIA DE LAS ARTES

CON LA COLABORACIÓN DE

\begin{tabular}{|c|c|c|}
\hline 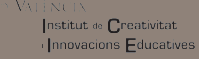 & $\begin{array}{l}\text { VNIVIRSIIA } \\
\text { In VVIIINCI Departament de Filosofia }\end{array}$ & 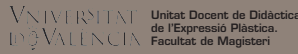 \\
\hline $\begin{array}{l}\text { TitTicA } \\
\text { SoFFA }\end{array}$ & 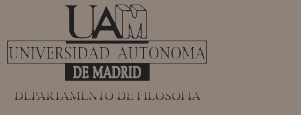 & $\begin{array}{l}\text { UAB } \\
\text { Universitat Autònoma } \\
\text { de Barcelona }\end{array}$ \\
\hline
\end{tabular}

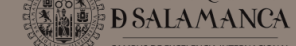

https://ojs.uv.es/index.php/LAOCOONTE/index 